\title{
IMPROBIDADE ADMINISTRATIVA: PRESCRIÇÃO, PROCESSO E RESSARCIMENTO AO ESTADO
}

\author{
ADMINISTRATIVE MISCONDUCT: LIMITATION, PROCEEDINGS
}

AND RESTITUTION TO THE STATE

\author{
Michel Kurdoglian Lutaif* \\ Arthur Paku Ottolini Balbani** \\ Lucca Lopes Monteiro da Fonseca ${ }^{* * *}$
}

\begin{abstract}
Resumo:
Desde o advento da Constituição Federal de 1988, que tratou da prescrição de atos de improbidade administrativa de agentes públicos, perdura o debate sobre a imprescritibilidade das ações de ressarcimento ao erário em decorrência dos prejuízos gerados pelos mesmos, por conta da previsão de seu art. $37, \S 5^{\circ}$. A indefinição chegou ao fim com o julgamento do RE $852.475 / \mathrm{SP}$, no qual o STF fixou tese pela imprescritibilidade das ações de ressarcimento fundadas em improbidade administrativa dolosa, permanecendo prescritíveis nos demais casos, inclusive quando fundadas na modalidade culposa. Entretanto, a dúvida se manteve sobre o meio processualmente adequado para se buscar judicialmente o ressarcimento. $\mathrm{O}$ presente artigo se propõe a analisar as opções que o ordenamento nos dá sobre a operacionalização processual do ressarcimento ao erário e qual a solução que vem sendo adotada pela jurisprudência.
\end{abstract}

Palavras-chave: Improbidade administrativa. Ressarcimento. Prescrição. Operacionalização processual.

\begin{abstract}
:
Since the enactment of the 1988 Federal Constitution, which dealt with the limitation in case of administrative misconduct acts by public officers, the debate on the no limitation in case of restitution of the losses has persisted, due to the provision of article $375^{\text {th }}$ paragraph of that Constitution. The lack of definition came to an end with the judgment of the Extraordinary Appeal 852.475/SP, in which the Brazilian Federal Supreme Court established a rule for the no limitation in the restitution lawsuits based on the intentional administrative misconduct, whereas the other cases remaining under limitation, in case of fault of the public officer. However, the doubt remained about the adequate procedural means to seek restitution in courts. This article offers an analysis of the different options in Brazilian Law for the State to get restitution, and the rule adopted by the Courts.
\end{abstract}

Keywords: Administrative misconduct. Restitution to the State. Limitation. Proceedings.

\footnotetext{
Mestrando em Direito do Estado pela Faculdade de Direito da Universidade de São Paulo e advogado. E-mail: michel.lutaif@usp.br.

** Bacharel em Direito pela Faculdade de Direito da Universidade de São Paulo. Assistente Jurídico do Tribunal de Justiça de São Paulo. E-mail: abalbani@tjsp.jus.br.

*** Graduando em Direito na Faculdade de Direito da Universidade de São Paulo. E-mail: lucca.lopes@usp.br. 
Introdução

Desde a edição da Constituição de 1988 , a redação de seu art. 37 , $\S 5^{\circ}$ provocou a instalação de um grande celeuma doutrinário e jurisprudencial. Dividiam-se os doutrinadores e os aplicadores do Direito em duas grandes correntes, cada qual com seus méritos e deméritos: a primeira afirmava a prescritibilidade das ações ressarcitórias decorrente de dano ao erário, tal qual já ocorria com os demais ilícitos civis, entendendo pela aplicação do prazo genérico da lei de improbidade administrativa. Já a segunda corrente, contudo, prestava deferência à literalidade do texto constitucional e pugnava pela imprescritibilidade da pretensão punitiva da Administração, nestes casos.

O julgamento do Tema n. 897 de Repercussão Geral pelo Supremo Tribunal Federal, em agosto de 2018, aparentou ter sedimentado essa controvérsia e apontado que a legislação brasileira ora vigente trilha o segundo entendimento supracitado. Contudo, o fim deste capítulo tormentoso do direito administrativo e constitucional brasileiro inaugurou um novo questionamento: sendo tais ações imprescritíveis, qual seria o procedimento a ser adotado na via jurisdicional para a reparação do dano? Diversas correntes surgiram, comungando apenas certo grau de incompletude e desconfiança processual, não havendo, até a presente data, orientação assertiva de qual caminho deve trilhar a processualística.

No cerne deste debate, repousa um problema de difícil solução: a aparente incompatibilidade processual entre os regimes da improbidade administrativa (sujeita a procedimento especial) e da ação reparatória/indenizatória (sujeita ao procedimento comum). Nesse embate, não são poucos os argumentos que devem ser sopesados pelo aplicador do direito, uma vez que o quadro ora delineado mostra verdadeiro embate entre princípios do processo civil e do direito administrativo, de um lado, e as garantias individuais do cidadão, de outro. A obtenção de solução razoável, que concilie ambas as pretensões, assim, é medida que se impõe para o aprimoramento da técnica processual e a concretização do fim último destas ações.

O presente artigo, nestes termos, tenta suprir essa lacuna ainda pouquíssimo abordada pela doutrina pátria, expondo os pontos favoráveis e críticos de cada uma das interpretações possíveis das aplicações processuais do Tema n. 897, bem como as soluções que o Tribunal de Justiça de São Paulo encontrou para, nesse momento de incerteza, garantir a tramitação de seus processos. 
1. A imprescritibilidade das ações de ressarcimento ao erário por improbidade dolosa e o RE $852.475 / \mathrm{SP}$

José Fernando Simão (2013, p. 136) ensina que justiça e segurança jurídica são os fundamentos basilares dos institutos da prescrição e da decadência. Em ilustrativa síntese, o autor expõe que "a prescrição e a decadência geram uma tranquilidade social em decorrência da certeza de que o tempo resolve todos os problemas, ainda que não haja qualquer ação humana para resolvê-los".

A questão do ressarcimento ao erário de prejuízos derivados de atos de improbidade já prescritos, contudo, não é pacífica no país. Por um lado a doutrina, com poucas exceções, adota a tese de que o art. $37, \S 5^{\circ}$, da Constituição Federal não obsta a pretensão de reparação dos prejuízos causados pelo agente mesmo que se verifique o lapso temporal da prescrição em relação à ação principal de improbidade administrativa. Por outro, ainda há dissonância em diversos julgados pelos tribunais do país, ainda que o Supremo Tribunal Federal se pronunciado por meio do RE 852.475/SP.

Nesse sentido, Maria Sylvia Zanella Di Pietro (2014, p. 926) sintetiza a interpretação majoritária da doutrina pátria sobre o tema:

São, contudo, imprescritíveis, as ações de ressarcimento
por danos causados por agente público, seja ele servidor
público ou não, conforme o estabelece o art. $37, \S 5^{\circ}$, da
Constituição. Assim, ainda que para outros fins a ação de
improbidade esteja prescrita, o mesmo não ocorrerá quanto
ao ressarcimento de danos.

Posição análoga é defendida por Odete Medauar (2008, p. 306), que destaca que o dispositivo constitucional "remete à lei a fixação de prazos de prescrição para ilícitos praticados por qualquer agente, servidor ou não, que causem prejuízo ao erário, ressalvadas as respectivas ações de ressarcimento".

E, ainda, exemplificando a questão, Marçal Justen Filho (2005, p. 696), ao tratar de hipótese de servidor que age com conduta passível de demissão:

E se aplica o prazo previsto na legislação administrativa para as faltas disciplinares puníveis com demissão, se for o caso. Assim, suponha-se que uma lei tivesse previsto o prazo de dois anos para a prescrição da punição com demissão. Decorrido esse prazo, a ação de improbidade no tocante à questão especifica da demissão estaria prescrita. Poderia ser exercitada para outros fins. Assim, poderia ser exercitada para obter a condenação do indivíduo a ressarcir os prejuízos acarretados aos cofres públicos ou, mesmo, sujeitá-lo à vedação ao exercício de cargos e funções públicas. [destaque no original] 
No âmbito constitucional, José Afonso da Silva (2014, p. 682-683) leciona que este dispositivo se apresenta como ressalva constitucional e inafastável à máxima de que o Direito não socorre os que ficam inertes. Isto é, neste caso, a Administração ou o Ministério Público, mesmo que não ajuízem a correspondente ação de improbidade administrativa, poderão se valer da reparação aos prejuízos causados.

Como se vê, é vasto o lastro doutrinário acerca do posicionamento de que o $\S 5^{\circ}$ do art. 37 consagra a imprescritibilidade da ação de ressarcimento ao erário dos prejuízos causados por agente ímprobo. Contudo, ainda há defensores de visão mais restritiva do dispositivo, a exemplo de Celso Antônio Bandeira de Mello, ao defender que o legislador constituinte visou tão somente separar os prazos de prescrição da condenação por improbidade da pretensão ressarcitória pelo Estado.

Síntese da visão do autor e crítica à mesma é feita por Maria Sylvia Zanella Di Pietro (2014, p. 926-927), que expõe seus principais argumentos:

Alguns autores vêm defendendo ponto de vista oposto. É o caso de Celso Antônio Bandeira de Mello, que, na $28^{\mathrm{a}}$ edição do seu Curso de Direito Administrativo (2011:1073), confessa ter mudado o seu entendimento. Ele expressamente declara estar aceitando o argumento apresentado por Emerson Gabardo em conferência proferida no Congresso Mineiro de Direito Administrativo, realizado em maio de 2009, no sentido de que, se adotada a imprescritibilidade, 'restaria consagrada a minimização ou eliminação prática do direito de defesa daquele a quem se houvesse increpado dano ao erário, pois ninguém guarda documentação que lhe seria necessária além de um prazo razoável, de regra não demasiadamente longo'. Alega também que, quando quis adotar a regra da imprescritibilidade, a Constituição o fez expressamente, como no artigo $5^{\circ}$, LII e LXIV. A seu ver, o que se tem de extrair do artigo $37, \S 5^{\circ}$, é 'a intenção manifesta, ainda que mal expressada, de separar os prazos de prescrição do ilícito propriamente, isto é, penal, ou administrativo, dos prazos das ações de responsabilidade, que não terão porque obrigatoriamente coincidir. Assim, a ressalva para as ações de ressarcimento significa que terão prazos autônomos em relação aos que a lei estabelecer para as responsabilidades administrativa e penal'.

Em contraponto à visão de Bandeira de Mello, Di Pietro (2014, p. 927) destaca que o argumento parece frágil, uma vez que a norma visou proteger o interesse público, e que a exceção à regra da prescritibilidade configura um alerta aos agentes responsáveis de que a qualquer momento podem ser acionados para restituir os prejuízos causados. 
Já na jurisprudência, o grande divisor de águas quanto ao ressarcimento ao erário a partir de ações de improbidade administrativa foi o RE 852.475/SP, julgado pelo Supremo Tribunal Federal em agosto de 2018 (BRASIL, 2018).

DIREITO CONSTITUCIONAL. DIREITO
ADMINISTRATIVO. RESSARCIMENTO AO ERÁRIO.
IMPRESCRITIBILIDADE. SENTIDO E ALCANCE DO
ART. 37, § 5०, DA CONSTITUIÇÃO. 1. A prescrição é
instituto que milita em favor da estabilização das relações
sociais. 2. Há, no entanto, uma série de exceções explícitas
no texto constitucional, como a prática dos crimes de
racismo (art. $5^{\circ}$, XLII, CRFB) e da ação de grupos
armados, civis ou militares, contra a ordem constitucional
e o Estado Democrático (art. $5^{\circ}$, XLIV, CRFB). 3. O texto
constitucional é expresso (art. 37, § $5^{\circ}$, CRFB) ao prever
que a lei estabelecerá os prazos de prescrição para ilícitos na
esfera cível ou penal, aqui entendidas em sentido amplo, que
gerem prejuízo ao erário e sejam praticados por qualquer
agente. 4 . A Constituição, no mesmo dispositivo (art. 37 ,
§ $5^{\circ}$, CRFB) decota de tal comando para o Legislador as
ações cíveis de ressarcimento ao erário, tornando-as, assim,
imprescritíveis. 5 . São, portanto, imprescritíveis as ações de
ressarcimento ao erário fundadas na prática de ato doloso
tipificado na Lei de Improbidade Administrativa. 6. Parcial
provimento do recurso extraordinário para (i) afastar a
prescrição da sanção de ressarcimento e (ii) determinar
que o tribunal recorrido, superada a preliminar de mérito
pela imprescritibilidade das ações de ressarcimento por
improbidade administrativa, aprecie o mérito apenas quanto
à pretensão de ressarcimento.

Quando do julgamento do recurso, fixou-se tese pela imprescritibilidade das ações de ressarcimento ao erário fundadas em ato doloso de improbidade administrativa. Os casos de reparação civil da improbidade em modalidade culposa, contudo, permaneceriam prescritíveis, observando a regra geral, em entendimento liderado pelo voto do Ministro Edson Fachin, vencida a corrente capitaneada pelo Ministro Alexandre de Moraes.

Apesar da visão majoritária da doutrina ter sido chancelada pelo entendimento do Supremo Tribunal Federal em sede de repercussão geral - neste que é o Tema n. 897 da Corte -, permanecem ainda dúvidas sobre o meio adequado para o processamento das referidas ações reparatórias. 
2. A operacionalização processual do ressarcimento e problemática da prova em caso de prescrição da ação de improbidade

O julgamento do RE $852.475 / \mathrm{SP}$, com a respectiva tese em repercussão geral, bateu o martelo a respeito da imprescritibilidade da pretensão de ressarcimento ao erário, fixando, nos termos do voto dissidente, vencedor, do Ministro Edson Fachin, a questão do elemento subjetivo como sendo determinante. Havendo improbidade dolosa, a pretensão de ressarcimento ao erário é imprescritível.

Entretanto, pela análise dos debates do julgamento do recurso no Supremo Tribunal Federal, notamos que uma questão de grande importância permaneceu sem definição clara. Trata-se da operacionalização processual da pretensão de ressarcimento ao erário. Em outras palavras, qual seria o meio processualmente correto para que esse ressarcimento aos cofres públicos pudesse ser cobrado do agente ímprobo. Tal discussão acentua sua importância principalmente em casos em que a ação condenatória de improbidade administrativa já estiver prescrita.

Este ponto pode ser observado nos debates do Supremo no curso da RE 852.475/SP (BRASIL, 2018), sendo iniciado pelo Ministro Relator Alexandre de Moraes, conforme se nota abaixo:

Mas, em relação à questão de improbidade - e tive a oportunidade de tentar salientar em meu voto -, os dois grandes problemas que foram gerados com essa criação por parte da doutrina e, depois, jurisprudencial - como Vossa Excelência colocou -, por parte do Superior Tribunal de Justiça, foram acarretar, primeiro, que a responsabilidade por ressarcimento ao erário, por ato de improbidade, não teria necessidade nem de seguir a lei de improbidade - eu citei até a manifestação da União, ou seja, seria uma mera ação de ressarcimento, sem aquelas etapas de defesa previstas pela improbidade - e, segundo, não haveria a necessidade de comprovar a improbidade. Ou seja, bastariam meros indícios, o que foi-se transformando numa responsabilidade objetiva.

No trechomencionado, o Ministro expõe a problemática da operacionalização processual, levantando duas principais soluções que se colocam no debate, as quais são mais profundamente tratadas ao longo da discussão no STF. Essas soluções seriam a via processual própria da improbidade administrativa - com proposição de Ação Civil Pública, fundada na Lei n. 8.429/92 - ou a via da ação autônoma de ressarcimento, a qual consiste em simples ação indenizatória cuja beneficiária é a Fazenda Pública.

De pronto, tem-se que nenhuma das suas soluções ali colocadas se mostra impassível a críticas. Quanto à primeira, sobre a utilização da via processual própria da 
improbidade, há óbice formal, pois haveria o real processamento de uma ação prescrita, conforme reafirma o Ministro Ricardo Lewandowski no curso no mesmo julgamento (BRASIL, 2018):

Seria uma transferência de um patrimônio público para a esfera privada de alguém, sem que se possa cogitar de um ilícito. Porque de improbidade não se pode mais falar, pois a pessoa não se defende mais da improbidade.

Já sobre a segunda solução, de ação autônoma, os Ministros Alexandre de Moraes e Gilmar Mendes levantam preocupações relacionadas ao direito de ampla defesa e devido processo legal.

Esta última consideração sobre a ampla defesa merece maior ponderação, afinal, ela se subdivide em duas problemáticas. A primeira delas diz respeito à consequência prática de se criar uma verdadeira responsabilidade objetiva, que já vem mencionada no trecho destacado acima.

Para compreender este ponto, é necessário um passo atrás. Uma vez reconhecida a imprescritibilidade da ação de ressarcimento fundada em ato doloso, apesar da prescritibilidade do próprio ato de improbidade, temos um problema de prova. A ação de improbidade, prescritível, ainda é relevante em questão preliminar para ação de ressarcimento, esta imprescritível.

No caso de não haver ocorrido a prescrição da ação principal de improbidade, não há maiores discussões, pois a condenação do agente por ato ímprobo doloso já configura desde logo a imprescritibilidade de eventual ação de ressarcimento. Problema maior se verifica nos casos em que a ação principal de improbidade já esteja prescrita, pois eventual ação de ressarcimento somente seria cabível se comprovado o dolo do ato de improbidade em si.

Nessa seara se enquadra a mencionada criação de uma verdadeira hipótese de responsabilidade objetiva. O que de fato ocorreria seria a transmissão desse juízo de julgamento sobre a existência de improbidade dolosa do Poder Judiciário ao Ministério Público, no momento da proposição da ação de ressarcimento, acomodando a questão como preliminar. Por essa lógica, meros indícios da ocorrência de improbidade dolosa já bastariam para superar a questão preliminar, sendo o julgamento do ressarcimento pautado na simples ocorrência do dano e existência de nexo causal.

Salta aos olhos a inconstitucionalidade desta hipótese, haja vista afronta ao art. $37, \S 4^{\circ}$ da Constituição Federal, o qual lido conjuntamente com os arts. $9^{\circ}, 10,10-\mathrm{A}$ e 11 da Lei n. 8.429/92 dita a responsabilidade subjetiva quanto aos tipos de improbidade administrativa. Sequer os Ministros defensores da via da ação autônoma nos debates do Supremo enxergaram razoabilidade nessa opção, o que restou claro pelas falas dos 
Ministros Luiz Fux e Rosa Weber a respeito da necessidade processual de comprovação do alegado e conformidade do processo aos corolários do devido processo legal.

Extrai-se, portanto, da defesa de alguns Ministros pela via da ação autônoma - especialmente considerando a interpretação conjunta com a fala da Ministra Rosa Weber no sentido de que "declara-se a existência de um ato de improbidade administrativa autorizador de uma condenação, premissa de uma condenação a ressarcimento do erário" (BRASIL, 2018) -, que existe uma terceira opção de via processual que se subdivide da ação autônoma, versando sobre a questão do incidente processual na ação de ressarcimento autônoma, para que houvesse definição sobre a ocorrência ou não de improbidade dolosa.

Esse entendimento, mesmo que supere as críticas acerca da criação de uma modalidade de responsabilidade objetiva e da transferência do juízo sobre a ocorrência de improbidade do Judiciário ao Ministério Público, também não está ileso. Tal proposta leva, novamente, à consideração do Ministro Alexandre de Moraes a respeito da ampla defesa e do devido processo legal, agora em sua segunda subdivisão, a qual toma por base uma das principais diferenças entre as vias da ação de improbidade e da ação autônoma, que é o rito. A via da Ação Civil Pública fundada na improbidade segue um rito diferenciado, previsto na própria Lei n. 8.429/92, o qual toma por base o rito ordinário, mas possui fases de defesa e apuração a mais, enquanto a ação autônoma de ressarcimento, sendo indenizatória, segue o rito ordinário do processo civil.

As principais diferenças entre os procedimentos adotados por uma via processual e por outra se dão quanto à existência, no processamento da improbidade, de fase pré-judicial relativa à apuração dos fatos por comissão processante de autoridade administrativa, dos arts. 14 a 16 da Lei n. 8.429/92. E na ação principal, por sua vez, quanto à existência de fase de juízo de admissibilidade e adequação da ação, com defesa prévia do acusado, anteriormente à citação do réu, do art. $17, \S \S 7^{\circ}$ e $8^{\circ}$, também da Lei n. $8.429 / 92$, as quais não se apresentam na ação indenizatória simples.

A razão de ser dessas fases extras que a Lei de Improbidade Administrativa impõe sobre o processamento de suas ações correlatas se dá devido à dificuldade relacionada na comprovação da violação de conceito jurídico aberto e ainda indeterminado, qual seja, a probidade administrativa.

Paralelamente, deve-se ter em mente que em todas as vezes que se julga uma ação de ressarcimento ao erário com fundamento em improbidade administrativa, temse de plano, necessariamente, um julgamento de improbidade, seja porque efetivamente houve a respectiva ação ou não. E em não havendo julgamento anterior, o ato está sendo julgado como ímprobo, implícita ou explicitamente, na ação que objetiva o ressarcimento. Assim, tendo isso por pressuposto, a via processual da ação autônoma, não possuindo fases extras, acaba por realizar, de fato, um julgamento de improbidade com menos oportunidade de defesa do réu, o que viola a ampla defesa e o devido processo legal. 
Assim, são extraídas algumas conclusões preliminares. Primeiramente, o ordenamento parece nos disponibilizar três vias processuais para buscar a pretensão de ressarcimento ao erário com fundamento na improbidade administrativa dolosa, quando prescrita a ação de improbidade: (i) processar como se improbidade fosse, com o rito da Lei n. 8.429/92, apenas aplicando a sanção de ressarcimento ao erário, ao final; (ii) ação autônoma - indenizatória -, tomando a improbidade dolosa como pressuposta; e (iii) ação autônoma com incidente processual para averiguar a ocorrência de improbidade dolosa.

Em segundo lugar, temos que nenhuma das vias é isenta a críticas. Afinal a primeira hipótese apresenta vício formal, de haver processamento de uma ação prescrita; a segunda estabelece responsabilidade objetiva e transfere ao MP o juízo de existência da improbidade dolosa; e a terceira, por sua vez, cerceia defesa ao julgar, de fato, a ocorrência de improbidade dolosa com menos oportunidades de defesa para o acusado do que prevê a Lei de Improbidade Administrativa.

Contudo, muito embora todas as hipóteses apresentem problemas, em primeira análise, de perspectiva ainda teórica, nos parece que a primeira hipótese, de processar como se improbidade fosse, apenas aplicando a sanção de ressarcimento ao erário, seria a mais adequada para os casos relatados.

3. Análise jurisprudencial: como a processualística fixada no Tema n. 897 tem sido confrontada pelo Tribunal de Justiça de São Paulo

Fixadas as premissas teóricas deste artigo nos itens anteriores e superadas as discussões acerca das possíveis soluções processuais encontradas na teoria para superar o impasse causado pela redação dúbia da tese do Tema n. 897 de Repercussão Geral, necessário analisar como o Tribunal de Justiça de São Paulo (TJ-SP) tem decidido sobre o tema.

Antes, contudo, cabe esclarecimento acerca do recorte metodológico para a análise jurisprudencial. Ainda que a análise dos julgados dos Tribunais Superiores seja de extrema relevância, uma vez que a decisão ali tomada serve de orientação, ainda que sem força vinculante, para todo o território nacional, é certo que ainda são escassas as decisões que confrontem o aspecto processual do Tema n. 897. Isso, sobretudo, por ainda ser recente o seu trânsito em julgado, ocorrido no final de 2019, de modo que ainda não decorreu tempo para que as demandas percorressem seu curso processual natural até desembocarem no Superior Tribunal de Justiça.

Ainda, considerando que o TJ-SP é o tribunal brasileiro de maior porte, respondendo, anualmente, por mais de cinco milhões de novos casos (BRASIL, 2019, p. 30), a análise de seus precedentes é um retrato relevante do que pode ser projetado 
de modo geral na jurisprudência nacional, considerando, ademais, a heterogeneidade da Seção de Direito Público da Corte.

A tendência verificada nos julgados do TJ-SP, como se mostrará adiante, é por prestar deferência à solução processual que privilegie o trâmite regular da ação civil pública por ato de improbidade administrativa, aplicando apenas a pena de condenação ao ressarcimento ao erário.

Um dos primeiros julgados da Corte Bandeirante a tratar do tema foi a Apelação Cível n. 1003073-55.2017.8.26.0587, julgada pela $5^{\text {a }}$ Câmara de Direito Público (SÃO PAULO, 2019a). Na ocasião, o Ministério Público havia ajuizado ação civil pública por ato de improbidade administrativa, mas pugnado exclusivamente pela condenação dos requeridos à pena de dano ao erário, já vislumbrando a prescrição das demais penas. A relatora, ao reformar a sentença e reconhecer a prescrição da pretensão punitiva, evidenciou em seu voto que é necessário primeiro proceder a uma análise do mérito da ação de improbidade, concluindo pela natureza de seu aspecto volitivo, para apenas depois passar a apreciar a prescrição ou não da conduta, invertendo a ordem tradicional de prejudicialidade prevista no $\mathrm{CPC}$, na qual se analisaria primeiro a prescrição para apenas após adentrar ao mérito.

Veja-se que a adoção da inversão desta fase processual, em concreto, foi de suma importância para o deslinde da controvérsia: no julgado em comento, o Primeiro Grau havia entendido pela procedência do pedido condenatório, reconhecendo a improbidade dolosa e, consequentemente, sua imprescritibilidade. Ante o apelo recursal pugnando pela prescrição da pretensão ministerial, fez-se necessário adentrar ao mérito para, reanalisando o caso, desqualificar a conduta de dolosa para culposa e, assim, permitir o reconhecimento da prescrição.

Postura análoga também se verifica no julgamento da Apelação n. 000237277.2002.8.26.0348, julgada pela $4^{\text {a }}$ Câmara de Direito Público (SÃO PAULO, 2019b), na qual o procedimento adotado pelo julgado anterior foi repetido, procedendo-se à análise do mérito em si, com determinação do elemento volitivo da conduta, fundamental para o enquadramento da demanda no Tema n. 897 de Repercussão Geral, e apenas então analisar a preliminar.

Nota-se, nestes casos ajuizados anteriormente ao julgamento em definitivo do Tema n. 897, que pouco poderia ser feito pelos Tribunais: são processos que, como no segundo exemplo, já se encontravam em grau recursal ou em fase final de instrução probatória quando sobreveio a determinação de suspensão dos processos (BRASIL, 2016), em setembro de 2016, razão pela qual a solução encontrada, de inversão entre apreciação de mérito e apreciação da preliminar, partindo-se de ação já ajuizada, se mostrou a mais adequada do ponto de vista da economia processual e da própria segurança jurídica, uma vez que, ao propor ambas as ações, não tinha o Parquet como prever a existência de 
múltiplos caminhos processuais para a pretensão reparatória fundada em ato doloso de improbidade administrativa.

Situação diversa, contudo, toca aqueles processos que foram ajuizados posteriormente ao julgamento de mérito do Tema n. 897, mesmo antes de seu trânsito em julgado, ou nos quais ainda não havia se dado o recebimento da petição inicial. Nestes casos, haveria a possibilidade de se adotar a integralidade dos caminhos propostos no item anterior. Contudo, a análise da jurisprudência revela uma postura tanto do TJ-SP como do Ministério Público Estadual - em regra, o proponente destas ações - no sentido de optar pela técnica de inversão de fases, em detrimento das demais opções.

Ao julgar o Agravo de Instrumento n. 2070985-96.2019.8.26.0000, a 13 Câmara de Direito Público (SÃO PAULO, 2019c), analisando caso no qual a tese de prescrição havia sido apresentada em sede de defesa prévia, decidiu que seria possível o deslinde da demanda logo nesta fase processual, com extinção do feito, sob o fundamento de que o Ministério Público havia imputado, na exordial, conduta culposa ao requerido, razão pela qual sequer seria necessário aguardar dilação probatória para proceder à análise da incidência, ou não, do Tema n. 897.

O caso, em si, é peculiar por ser nele incontroverso que o réu cometera ato ímprobo culposo, o que foge da regra geral das ações civis de improbidade administrativa. Ainda assim, não se pode concordar com a integralidade de sua tese: se o julgador não é adstrito, nas ações de improbidade administrativa, à tipificação feita na exordial - uma vez que se está a apurar a existência de ato de improbidade administrativa em sentido amplo, o qual pode se enquadrar, a depender do conjunto probatório, em quaisquer dos quatros subtipos de atos ímprobos -, então não há óbice para que, no curso da ação, se desqualifique a conduta, reconhecendo traço distintivo não vislumbrado na exordial, já que, ao menos nesta fase inicial do processo, ainda vigora o princípio in dubio pro societate (NEVES; OLIVEIRA, 2018, p. 290).

E, ainda que se acolha a tese exarada pela Câmara Julgadora, o precedente deve ser visto de maneira restritiva: a admissibilidade do acolhimento de prescrição em sede de defesa prévia apenas deve ser possível quando incontroversa a natureza culposa da conduta, não sendo possível, de pronto, a desqualificação da conduta ou a assunção de que esta ocorrera em modalidade menos grave, justamente por força do princípio orientativo supracitado.

A despeito dessa ressalva ao julgado, dele se extrai informação muito significante. Ao reconhecer a imprescindibilidade da defesa prévia, sinalizou a Corte naquele momento que não poderia ser trilhado o caminho alternativo que preconiza a distinção entre a ação indenizatória e a ação de improbidade, sendo esta apenas incidente da primeira, uma vez que a natureza especial do procedimento da ação de improbidade 
imporia o seu rito processual, em detrimento do procedimento comum a que se sujeita a ação reparatória.

Tal sinalização, de fato, foi incorporada à jurisprudência da Corte, que passou a aplicá-la com mais afinco. Quando do julgamento do Agravo de Instrumento n. 2120744-29.2019.8.26.0000, a $3^{\text {a }}$ Câmara de Direito Público (SÃO PAULO, 2019d) asseverou entendimento de que mesmo as ações de improbidade cuja única pena seja a de reparação ao erário devem se sujeitar ao procedimento próprio das ações de improbidade administrativa, seja pela sua natureza peculiar, seja pelo fato das sanções da Lei $n$. 8.429/92 não serem cumulativas, sendo possível ao autor da ação pugnar pela aplicação de uma ou mais sanções.

E, nos casos em que transcorrido o prazo prescricional das sanções remanescentes, caso sejam postuladas pelo autor, a Corte não deixa dúvidas de que seu reconhecimento é imperativo, mesmo sem a apreciação do mérito, restringindo, assim, o procedimento sui generis apenas para o pedido de reparação de danos ao erário. Nesse sentido, depreende-se de interessante julgado da $9^{\text {a }}$ Câmara de Direito Público (SÃO PAULO, 2019e), referente a caso no qual tal problemática se afigurou presente, que, em sendo a reparação ao erário a única sanção de cuja fluência do prazo prescricional não independe de aspectos probatórios, seria esta, em regra, o único óbice ao reconhecimento de prescrição em juízo de cognição sumária.

Vê-se, deste modo, que a existência de múltiplas opções processuais para a execução da pretensão reparatória fundada em ato doloso de improbidade administrativa, ao ver da jurisprudência do Tribunal de Justiça de São Paulo, deve necessariamente levar em conta (i) a natureza peculiar da ação civil pública de improbidade administrativa, que possui fases diferenciadas da ação reparatória, sujeita ao procedimento comum e (ii) a impossibilidade de se constatar, a priori, a ocorrência ou não da prescrição, ante a incidência do princípio in dubio pro societate e a consequente vedação à presunção de culpa. Em resumo, extrai-se da jurisprudência da Corte paulista postura que diverge em parte das proposições do Supremo Tribunal Federal e que tende a simplificar a dinâmica processual, ao mesmo tempo em que assegura os direitos do réu. 
Conclusão

A prescrição é instituto jurídico que pacifica as relações sociais pelo tempo. A Constituição Federal, contudo, abriu espaço para exceções, dentre as quais a possibilidade de ressarcimento ao erário de prejuízos causados ao Estado por atos dolosos de improbidade administrativa.

Com redação polêmica, o tema é discutido extensamente na doutrina, que teve sua maioria acompanhada por entendimento vinculante do Supremo Tribunal Federal no RE 852.475/SP, que tomou por critério relevante o elemento típico subjetivo.

Contudo, a decisão em sede de repercussão geral não exauriu o assunto, pois manteve em aberto a questão do meio processualmente correto de buscar a pretensão de ressarcimento.

Dos debates realizados no Supremo, identificam-se as diferentes correntes sobre a operacionalização processual do ressarcimento: (i) processar a ação como se improbidade fosse, com condenação apenas ao ressarcimento; (ii) processar ação autônoma com improbidade dolosa pressuposta e; (iii) processar ação autônoma com incidente para conhecimento da improbidade. Todas essas hipóteses, contudo, apresentam severas críticas.

Ao menos em teoria, a primeira opção aparenta ser a menos problemática, pois não transforma a apuração de improbidade com critérios de responsabilidade objetiva e tampouco possui mácula à ampla defesa e ao devido processo legal, em especial aos mecanismos de defesa previstos na Lei de Improbidade Administrativa.

E essa também foi a solução preferida dos Tribunais. A jurisprudência referente às ações propostas anteriormente ao Tema n. 897 inaugurou o entendimento de se processar as ações de ressarcimento ao erário como se fossem típicas ações de improbidade, mas com a única sanção de reparação do dano. Contudo, invertia-se a análise das matérias: primeiro se analisa o mérito em si para, apenas após, analisar a preliminar de prescrição.

Também as ações propostas posteriormente ao julgamento do STF seguiram esse entendimento, sob o fundamento assecuratório do direito de defesa dos acusados, maximizado pelo procedimento especial para apurar a prática de improbidade.

São Paulo, abril de 2020. 


\section{Referências}

BRASIL. Conselho Nacional de Justiça. Justiça em números 2019. Brasília: CNJ, 2019. Disponível em: https:/www.cnj.jus.br/wp-content/uploads/conteudo/arquivo/2019/08/justica_em_ numeros20190919.pdf. Acesso em:

BRASIL. Supremo Tribunal Federal. Recurso Extraordinário 852.475-SP. Despacho de suspensão (art. 1.035, § 5, $\mathrm{CPC} / 15$ ). Relator: Ministro Teori Zavascki. Recorrente: Ministério Público do Estado de São Paulo. Recorrido: Antônio Carlos Coltri e outros. Brasília, 21 jun. 2016. Diário de Justiça Eletrônico, Brasília, DF, 14 jun. 2016. Disponível em: https://stf.jusbrasil.com.br/ jurisprudencia/875997772/recurso-extraordinario-re-852475-sp-sao-paulo.

BRASIL. Supremo Tribunal Federal. Tribunal Pleno. Recurso Extraordinário 852.475/SP. Relator: Min. Alexandre de Moraes. Redator para o Acórdão: Min. Edson Fachin. Recorrente: Ministério Público do Estado de São Paulo. Recorrido: Antonio Carlos Coltri e outro(a/s). Brasília, DF, 8 ago. 2018. Diário de Justiça Eletrônico, Brasília, DF, 25 mar. 2019. Disponível em: https://stf. jusbrasil.com.br/jurisprudencia/768161402/recurso-extraordinario-re-852475-sp-sao-paulo/inteiroteor-768161412.

DI PIETRO, Maria Sylvia Zanella. Direito administrativo. 27. ed. São Paulo: Atlas, 2014.

JUSTEN FILHO, Marçal. Curso de direito administrativo. São Paulo: Saraiva, 2005.

MEDAUAR, Odete. Direito administrativo moderno. 12. ed., rev. e atual. São Paulo: Revista dos Tribunais, 2008.

MELLO, Celso Antônio Bandeira de. Curso de direito administrativo. 28. ed. São Paulo: Malheiros, 2011.

NEVES, Daniel Amorim Assumpção; OLIVEIRA, Rafael Carvalho Rezende. Manual de improbidade administrativa: direito material e processual. 6. ed. rev., atual. e ampl. São Paulo: Método, 2018.

SÃO PAULO. Tribunal de Justiça do Estado de São Paulo. $5^{\text {a }}$ Câmara de Direito Público. Apelação Cível n. 1003073-55.2017.8.26.0587. Relatora: Des. Heloísa Martins Mimessi. Apelantes: Juan Manoel Pons Garcia e Antonio Luiz Vasques Carneiro. Apelado: Ministério Público do Estado de São Paulo. São Paulo, SP, 22 jul. 2019. Diário de Justiça Eletrônico, São Paulo, 24 jul. 2019a.

Disponível em: https://j-sp.jusbrasil.com.br/jurisprudencia/896029700/apelacao-civel-ac10030735520178260587-sp-1003073-5520178260587/inteiro-teor-896029928.

SÃO PAULO. Tribunal de Justiça do Estado de São Paulo. Agravo de Instrumento n. 207098596.2019.8.26.0000. Relator: Des. Borelli Thomaz. Agravante: Reinaldo Custódio da Silva. Agravado: Ministério Público do Estado de São Paulo. São Paulo, SP, 12 jun. 2019. Diário de Justiça Eletrônico, São Paulo, 13 jun. 2019c. Disponível em: https://tj-sp.jusbrasil.com.br/jurisprudencia/721244147/ agravo-de-instrumento-ai-20709859620198260000-sp-2070985-9620198260000/inteiroteor-721244176. 
SÃO PAULO. Tribunal de Justiça do Estado de São Paulo. Agravo de Instrumento n. 212074429.2019.8.26.0000. Relator: Des. Paola Lorena. Agravante: Artur Luiz Alves Tizo. Agravado: Ministério Público do Estado de São Paulo. São Paulo, SP, 22 out. 2019. Diário de Justiça Eletrônico, São Paulo, 24 out. 2019d. Disponível em: https://j-sp.jusbrasil.com.br/jurisprudencia/897628939/ agravo-de-instrumento-ai-21207442920198260000-sp-2120744-2920198260000/inteiroteor-897629018.

SÃO PAULO. Tribunal de Justiça do Estado de São Paulo. Agravo de Instrumento n. 216442549.2019.8.26.0000. Relator: Des. Carlos Eduardo Pachi. Agravante: Renato Netto Cardoso. Agravado: Ministério Público do Estado de São Paulo. São Paulo, SP, 23 set. 2019. Diário de Justiça Eletrônico, São Paulo, 23 set. 2019e. Disponível em: https://j-sp.jusbrasil.com.br/jurisprudencia/760551814/ agravo-de-instrumento-ai-21644254920198260000-sp-2164425-4920198260000/inteiroteor-760551834.

SÃO PAULO. Tribunal de Justiça do Estado de São Paulo. Apelação Cível n. 000237277.2002.8.26.0348. Relator: Des. Osvaldo Magalhães. Apelantes: José Carlos Grecco Pavecol - Pavimentação Empreendimentos e Comércio LTDA. Apelado: Ministério Público do Estado de São Paulo. São Paulo, SP, 12 ago. 2019. Diário de Justiça Eletrônico, São Paulo, 13 ago. 2019b. Disponível em: https://tj-sp.jusbrasil.com.br/jurisprudencia/901345864/apelacao-civel-ac23727720028260348-sp-0002372-7720028260348/inteiro-teor-901346076.

SILVA, José Afonso da. Curso de direito constitucional positivo. 37. ed. São Paulo: Malheiros, 2014.

SIMÃO, José Fernando. Prescrição e decadência: início dos prazos. 1. ed. São Paulo: Atlas, 2013. 
